\title{
Hardiness as resource of adaptation and a teacher's professional and personal development
}

\author{
Liudmila V. Shukshina ${ }^{1}$, Rina S. Khammatova², Lyudmila A. Bezborodova ${ }^{3}$, Larisa E. Zotova ${ }^{4}$, Tatyana L. Khudyakova ${ }^{5}$,
} Irina V. Kokhova ${ }^{6}$, Igor G. Kochetkov ${ }^{7}$

\begin{abstract}
Objectives: The article addresses the problem of the interaction between the teacher and an inclusive educational environment in the context of the environment impact on the professional and the teacher's personal development. The author(s) have shown the predominance of subjective difficulties in interacting with an inclusive educational environment; the educators' need for support and searching for resources for the effective implementation of inclusive education.

Materials: The article also contains the results of an empirical study on a sample of teachers of general education institutions $(n=118)$ with the use of diagnostic tools: the author's interview "Identifying the characteristics of the teacher's work in the context of the implementation of inclusive education", "Hardiness test", the technique of "job satisfaction".

Results: The results of the study made it possible to establish the interrelationships between hardiness and work satisfaction and teachers' relations in professional circles, which makes it possible to consider hardiness as a teacher's significant resource for adapting to an inclusive educational environment.

Conclusions: The revealed interrelationships between hardiness and job satisfaction serve as the foundation to work out mechanisms and methods of psychological assistance in the teacher's effective adaptation in the process of overcoming difficulties in professional activity. The data obtained during the study establishes the basis for designing development programs and professional career counseling for teachers.
\end{abstract}

Keywords: inclusive education, difficulties of professional activity, personal resources to overcome difficulties, job satisfaction, hardiness

\section{INTRODUCTION}

At the stage of implementing inclusive education, the teacher has a huge responsibility to change both approaches to the organization and planning of the educational process and the educational environment as a whole. At the same time, the educational environment makes new demands on the teacher himself, on his personal qualities and resources. The teacher is forced to change himself, adapt to the new requirements of the environment, which creates a state of physical, emotional and mental stress, reduces satisfaction with professional activities, and also actualizes the problem of the teacher's searching for psychological help and support. We consider the teacher's adaptation process as adaptive interactions with the educational environment in the process of overcoming difficulties. All of the abovementioned prioritizes a study of both the problems of the teacher's professional difficulties and his personal resources that contribute to overcoming these difficulties in the implementation of inclusive education (1).

\section{METHODOLOGICAL FRAMEWORK}

The Modern studies show that the professional activity of a teacher is characterized by a high level of responsibility and stress. Over the past decades, the main stressful situations in professional activity have been identified, such as role

\footnotetext{
Plekhanov Russian University of Economics, Moscow, Russia.

2 The Sechenov First Moscow State Medical University, Moscow, Russia.

3 Moscow Pedagogical State University, Moscow, Russia.

4 Moscow Region State University, Moscow, Russia.

5 Voronezh State Pedagogical University, Voronezh, Russia.

6 Financial University under the government of the Russian Federation, Moscow Russia.

7 Ulyanovsk State University, Ulyanovsk, Russia.
}

Received: 18 Jun 2019, Accepted: 20 Sep 2019

Correspondence: Liudmila V. Shukshina

Plekhanov Russian University of Economics, Moscow, Russia.

E-mail: Liudmila.shukshina@yandex.ru

(c) 2019 by the authors; licensee Modestum Ltd., UK. This article is an open access article distributed under the terms and conditions of the Creative Commons Attribution License (http://creativecommons.org/licenses/by/4.0/).

Electronic Journal of General Medicine 
uncertainty, role overload and underload, role conflict, "unapproachable bosses", the use of one's own skills and abilities not in full, and also health impairments. G.V. Akopov (2) in his studies identifies the following groups of difficulties in the professional activity of teachers:

1. organizational ones (discipline, student behavior; large classes, extracurricular activities, classroom management, classroom leadership; time allocation in the lesson, work with parents, inexperience, scheduling, reports, lack of time, preparing and conducting class hours, a lot of reporting, the material base of the school, the lack of equipment, the office interior design, etc.);

2. psychological and pedagogical ones (contact, communication with children, relationships with students, inability to find an approach to children, arouse interest among children, establish a close rapport with children, work with teenagers, "problem" students, the desire to make the lesson interesting, the students' unwillingness to learn the subject, inability to stay in front of many people, lack of knowledge on a teenager's psychology, etc.) (3);

3. methodological ones (preparation for the lesson, drawing up a plan of lessons, lack of knowledge of the program, unfamiliarity with a textbook, lack of methodical literature, etc.)

4. relations in other staff members (relations with colleagues, administration, parents).

The indicated difficulties are aggravated at the stage of the implementation of inclusive education by emerging obstacles (barriers) in teaching children with special educational needs. Researchers identify the following among them:

- barriers of the "architectural" environment of the student - physical inaccessibility of the environment (for example, the lack of ramps and elevators at home and at school, the inaccessibility of transport between the house and the school, the absence of traffic lights with sound signal on the road crossing on the way to school, etc.);

- financial barriers, if necessary, additional costs for the organization of special pedagogical support;

- barriers of social relations - barriers that arise as a result of the relationship of students and the social contexts of their being. Otherwise, they are called "relational" or social barriers;

- barriers associated with professional attitudes among teachers of general and special education, an inflexible system for assessing students' achievements, and the insufficiency of the existing regulatory framework (4-12).

\section{A Sample, Techniques and Research Methods}

The analysis of the difficulties in a teacher's professional activity in the process of interaction with an inclusive educational environment, the consequences of these difficulties for a teacher, as well as the search for the ways to overcome them by teachers was the subject of research. One hundred and eighteen teachers of secondary schools of the city of Ulyanovsk and the Ulyanovsk region participated in the study.

As research methods, we used the author's interview "Identifying the characteristics of the teacher's work in the context of the implementation of inclusive education", "Hardiness test" (the authors - Leontiev, Rasskazova, (13)), the method of "Job satisfaction" by Rozanova (14). An interactive internet-based program for collecting, storing and processing personal data was used for statistical processing and analysis.

\section{RESULTS AND DISCUSSION}

In the course of the study, the subjective difficulties of teachers in the implementation of inclusive education were discovered. Fifty-six per cent of teachers said that they lacked professional competence in work. Fifty-six per cent of teachers feel disappointed that not all children can achieve the required results. The study showed that $51 \%$ of teachers experienced emotional overload in work. One of the factors that provoke emotional overload and stress of teachers is time pressure, which is mentioned by $31 \%$ of respondents. The time pressure regime takes away a lot of energy from the teacher. For some time, the body is able to withstand the race, but after the internal resources are exhausted, a turning point comes. If the time pressure is delayed for a long time, it is fraught for the teacher with physical and mental exhaustion, depression and insomnia. Among other factors, teachers identify excessive control from the superiors (22\%). External control, which is carried out by the committee for supervision and control, the Ministry of Education, administration, parents, provokes tension and is another stressful factor for the teacher.

A serious difficulty for the teacher in the emotional and professional aspect is the dissatisfaction on the part of the parents of children who do not have problems in learning and with health $(27 \%)$, and lack of understanding on the part of the parents of children with disabilities (22\%). Eleven per cent of teachers say that they have difficulty in controlling their own emotions.

The revealed difficulties cannot but affect the teacher's attitude to professional activity, his satisfaction with work. Work satisfaction is an integrative indicator that characterizes the well-being / disadvantage of the teacher in the course 
of professional activity. It incorporates an assessment of interest in the performed work, satisfaction with the relationship with colleagues and administrations of the educational institution, the level of claims of the teacher in professional activities, satisfaction with the conditions, organization of work, etc. (15). At the same time, a literature review survey on the problem of the teacher's professional difficulties made it possible to assume that the attitude to professional activity and satisfaction with it are largely determined by a person's qualities. Analyzing the difficulties of teachers in the implementation of inclusive education, it was found that $33 \%$ of the teachers participating in the study consider the lack of personal resources to overcome difficult situations as one of them. This confirms the answer of teachers to the question: "What resources help you overcome the difficulties of inclusive education?" Unfortunately, only $13 \%$ of respondents pointed out that their own personal qualities help them overcome situations of difficulties. In the course of the study, teachers were asked to clarify exactly what personal qualities help them overcome difficult situations. There were the following among them: responsibility, poise, sociability, artistry, creative approach to activity. But the majority of teachers found it difficult to answer the question (16-19).

The data obtained in the study allow us to pinpoint the problem of insufficient personal resources to overcome the identified difficulties as the most significant problem of the effective interaction of the teacher with an inclusive educational environment.

Among the teacher's personal resources, we pick out hardiness, which is the basic constituent of the teacher's personality and allows one to actively engage in situations of professional difficulties, to engage in search activity to find means to overcome these situations, withstand emotional stress, and use constructive behavioral strategies. Constructive overcoming of difficulties, in its turn, contributes to the positive emotional well-being of the teacher, increases selfesteem, satisfaction with work and relationships in professional circles and adaptability to professional activities in general.

The authors of the theory of hardiness Maddi, Khoshaba, Harvey (20) define it as a special personality disposition that characterizes the measure of a person's ability to withstand a stressful situation, while maintaining internal balance and not reducing the success of activity. The role of this personality variable in successful confronting stressful situations is especially emphasized. Hardiness is considered by the authors as an integrative personal education, which includes three components: involvement, control, risk taking, the expressiveness of which prevents the occurrence of internal stress in stressful situations.

One of the objectives of the study conducted was to gain some insight into the interrelationship between a teacher's hardiness and his satisfaction with work. During the study, two groups were formed, differentiated by the level of hardiness development: teachers with a low level of hardiness and teachers with a high and medium level of hardiness. According to the results of the study, we found statistically significant relationships between teachers' hardiness and their job satisfaction $(p<0.05)$.

This is indicative of the fact that teachers from the group with a low level of hardiness are not sufficiently adapted to their social environment, they often have conflicts with others for various reasons. Moreover, the researchers in their works indicate a stable predisposition of teachers to respond to all kinds of situations as "dangerous", where it is required "to stand up for oneself", "to defend oneself". The reason for this may be in the created conditions of competition, in which teachers found themselves with the introduction of new projects in the modern education system, the lack of cooperation among the teaching staff, and the development of a critical attitude towards staff from the administration. Without denying these points as a whole, we pinpoint the fact that teachers with a high and medium level of hardiness, being in the same conditions, are significantly more satisfied with the developing relations with staff members. This proves that the personal qualities and resources of teachers still dominate the satisfaction with relationships (21-24).

In the course of the study, we found a special role of the expression level of the teacher's involvement in his attitude to professional activity and job satisfaction. Teachers with a high level of involvement and hardiness tend to understand that in difficult situations it is important to keep abreast of events, in contact with people around us, devote maximum of efforts and time, attention to what is happening, to participate in what is happening. They appreciate their colleagues, are able to establish constructive relationships with its members, positively perceive students, take an active position in the educational process, seek support from others, which helps to relieve symptoms of emotional burnout, such as tension, anxiety, depression and a constructive emotional response. Such teachers are active in relations with students and themselves. They actively build them, which contributes to satisfaction with these relations. Teachers with a predominance of the attitude of involvement in solving problems are distinguished by less stressful and emotional "fixedness". The interrelation of hardiness revealed in the course of the study with satisfaction with one's position in a group of teachers $(p<0.01)$, due to the contribution of involvement, proves the abovementioned points (25). 
Involvement is positively correlated with the attitude towards the educational institution $(p<0.05)$ and the attitude towards the head of the educational institution $(p<0.05)$. This indicates that the higher the level of teachers' involvement, the more active their position in the educational process is. They are aware of their role in the activities of an educational institution, their own value, significance, and the ability to influence events. Accordingly, we can make the assumption that teachers with high indicators of hardiness and involvement have a high responsibility for their own life, and do not shift it to the leader and colleagues. Hardiness in general contributes to a positive reassessment of the significance of everything that happened to the individual, for its further growth.

\section{CONCLUSION}

The results of the study made it possible to establish the interrelationships between hardiness and work satisfaction and teachers' relations in professional circles, which makes it possible to consider hardiness as a teacher's significant resource for adapting to an inclusive educational environment. The revealed interrelationships between hardiness and job satisfaction serve as the foundation to work out mechanisms and methods of psychological assistance in the teacher's effective adaptation in the process of overcoming difficulties in professional activity. The data obtained during the study establishes the basis for designing development programs and professional career counseling for teachers.

\section{ACKNOWLEDGEMENTS}

The authors express their gratitude to the Natural sciences educational center of the Mordovian State Pedagogical Institute named after M.E. Evseviev for the granted opportunities to conduct the scientific research.

\section{REFERENCES}

1. Zotova LE. The role of personal resources in shaping the perception of educators about resource provision. Bulletin of Moscow State Regional University. Series: Psychological Sciences, 2018;2:114-24. https://doi.org/10.18384/2310-7235-2018-2-114-124

2. Akopov GV. The social psychology of education. Moscow: Prospect; 2000.

3. Salakhova VB, Oschepkov AA, Lipatova NV, Popov PV, Mkrtumova IV. Features of Social Attitudes and Value Orientations of Youths and Adolescents Prone to Auto-Aggressive Behavior. International journal of environmental \& science education, 2016a;11(16):9017-25.

4. Salakhova VB, Belinskaya DB, Erofeeva MA, Ulyanova IV, Zotova LE, Khammatova RS, Mizonova OV. Modern methods of diagnosing addiction to psychoactive substances: neurophysiological aspects. Electronic journal of general medicine, 2018;15(6):94-106. https://doi.org/10.29333/ejgm/100633

5. Mitin SN. Psychotherapeutic approach in the management of the development of educational systems. Simbirsk Scientific Journal Vestnik, 2016;4(26):31-9.

6. Masalimova AR, Mikhaylovsky MN, Grinenko AV, Smirnova ME, Andryushchenko LB, Kochkina MA, Kochetkov IG. The interrelation between cognitive styles and copying strategies among student youth. Eurasia Journal of Mathematics, Science and Technology Education, 2019;15(4):em1695. https://doi.org/10.29333/ejmste/103565

7. Erofeeva MA, Grinenko AV, Stanovova LA, Kosolapova NV, Mikhaylovsky MN, Rybina IA, Kochetkov IG. Motivation and motives of juvenile delinquents. EurAsian Journal of BioSciences, 2019;13:1-6.

8. Kovaleva NB. The Role of Reflection in the Development of a Culture of Collective Creativity. Azimuth of Scientific Research: Pedagogy and Psychology, 2015;4(13):120-3.

9. Makarova EV, Kryukova NI, Sizova ZhM, Grinenko AV, Erofeeva MA, Bukalerova LA. Divergence of Supreme Values of Russian World and Western Civilization Social And Philosophical Analysis. European Journal of Science and Theology, 2019;15(3):97-107.

10. Sokolovskaya IE, Grinenko AV, Miroshkin DV, Udodov AG, Egorova EV, Diatlova EV. The Eco-Psychological Approach in the Psychological Follow-Up Program for Children with Limited Abilities. Ekoloji, 2019;107:659-64.

11. Oschepkov AA, Salakhova VB. Features of life situations of young people tending to deviant behavior. Simbirsk Scientific Journal Vestnik, 2016;2(24):37-41.

12. Mukhametshin RZ, Kryukova NI, Beloborodova AV, Grinenko AV, Popova OV. Implementation of Efficient Energy Policy in Russia: Energy Consumption Monitoring and Problem Analysis. International Journal of Energy Economics and Policy, 2019;9(4):224-32. https://doi.org/10.32479/ijeep.7967

13. Leontiev DA, Rasskazova El. Vitality Test. Moscow: Meaning; 2006. 
14. Rozanova VA. Psychological paradoxes in management. Moscow: "Business School" "Intel-Synthesis"; 1997.

15. Salakhova VB, Bulgakov AV, Sokolovskaya IE, Khammatova RS, Mikhaylovsky MN. Substantive (Content-Related) Characteristics of Deviant Behavior as a Social and Psychological Phenomenon. International journal of environmental \& science education, 2016c;11(17):10609-22.

16. Masalimova AR, Chibakov AS. Experimental analytical model of conditions and quality control of vocational training of workers and specialists. Mathematics Education, 2016;11(6):1796-808.

17. Lekareva EE, Zaretskiy VV, Artamonova EG, Salakhova VB, Efimova OI, Kalinina NV. Comprehensive rehabilitation of minors with deviant and delinquent behavior: The experience of the Russian system of education. Eurasian journal of analytical chemistry. Eurasian Journal of Analytical Chemistry, 2018;13(1b):em84. https://doi.org/10.29333/ejac/102249

18. Grinenko AV, Gegel LA, Poleshchuk IA, Tutaeva DR, Pronina EV, Shchukina TV, Egorova EV. A governing and political orientation in the field of education. EurAsian Journal of BioSciences, 2019;13:1-6.

19. Salakhova VB, Ovsyanik OA, Shmeleva NB, Lvova EN, Shabanova OV. The Problem of Higher Education in the Executive System of Russian Government. International journal of environmental \& science education, 2016b;11(4):9883-9.

20. Maddi SR, Khoshaba DM, Harvey RH. The personality construct of hardiness, V: Relationships with the construction of existential meaning in life. Journal of Humanistic Psychology, 2011;51(3):369-88. https://doi.org/10.1177/0022167810388941

21. Kalenik EN, Salakhova VB, Mikhaylovsky MN, Zhelezniakova ME, Bulgakov AV, Oshchepkov AA. Psychophysiologic features and personal-adaptive potential of students with limited abilities. Electronic journal of general medicine, 2018;15(6):em98. https://doi.org/10.29333/ejgm/100635

22. Kalinina NV, Kalinin IV, Oschepkov AA, Salakhova VB, Simanovskay MA. The Use of Social Resources of Inclusive Educational Environment to Cope Difficult Situations by Adolescents. Mathematics education, 2016;11(7):252736.

23. Kovaleva NB. Text as the Point of Meeting and Misconception. Media Hermeneutics of Self-Conceptionsand Images. Pedagogy and education, 2016;3:238-48.

24. Salakhova VB, Gnedova SB, Emelyanenkova AV, Mikhailova IV, Sedunova AS, Enyashina NG. Individual characteristics of students in the course of professional development (as exemplified by the ulyanovsk region of russia). Asian Social Science, 2015;11(3):168-75. https://doi.org/10.5539/ass.v11n3p168

25. Salakhova VB, Oschepkov AA. Peculiarities of social groups of teenagers with deviant orientation. Simbirsk Scientific Journal Vestnik, 2017;2(28):46-54.

$\diamond \diamond \diamond \diamond \diamond \diamond \diamond$

http://www.ejgm.co.uk 